\title{
Duh, or the Role of IT in Teaching Comparative Politics
}

\author{
Charles Hauss, George Mason University
}

\section{A New Feature for PS}

Welcome to the first of a series of columns on technology and teaching Michael Gizzi of Mesa State College and I will prepare for $P S$. We have agreed to write two columns each per year, but welcome ideas and articles from all our colleagues, especiaily those with expertise in fields outside our own.

\section{Duh}

In keeping with $P S$ tradition that the December issue largely reports activities at APSA's Annual Meeting, I will devote this inaugural column to discussing what I learned from participating in a workshop I chaired on the role information technology (IT) can play in teaching comparative politics.

I'm a true believer in what IT can do. So, too, were four of the other five participants in the panel. Nonetheless, I asked them all to reflect self-critically on their own work and, by extension, the way many instructors are using new technologies in the classroom. I spoke in general. Ken Wedding, a teacher at Hopkins High School in Hopkins Minnesota, dealt with the web. Michael LeRoy of Wheaton College (IL) covered quantitative approaches, and Michael Kenney of the University of Florida discussed his experiences teaching an online version of the introductory course. Philip Giddings of the University of Reading (UK) and Gerry Drake of George Mason's Instructional Research
Center offered comments on the four presentations.

As the panel progressed, I noted how much what the other participants had to say reinforced three conclusions I had reached in my own analysis of IT use. The first is quite encouraging. The other two sent me back to the drawing board this fall.

As this realization dawned, I had a reaction a lot of students have in class once they take a step back from the material and see the answers become obvious: "Duh!".

\section{Active Learning}

I confess. I'm a technophile. I get jitters if I don't buy a new computer every year. I look at slashdot.org almost every day. I have even thought about going back to school and getting a B.S. in computer science.

However, I do not use IT solely to indulge my own "geek" tendencies. I, like my colleagues from the panel, use technology because I am convinced that doing so promotes active learning by leading students to ask more of their own questions and to answer them in more nuanced ways. Ken Wedding showed how he uses a fake web site for a real town, a plausible web site on a fake town, and a site visitors have to dig into a bit before they realize it is antisemitic and racist to help his students learn to assess material on the Internet. Michael LeRoy showed how he uses data from the World Values Study he compiled for MicroCase to get his Chris-

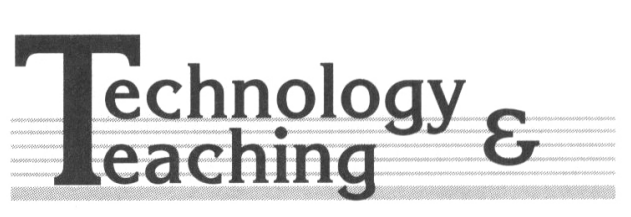

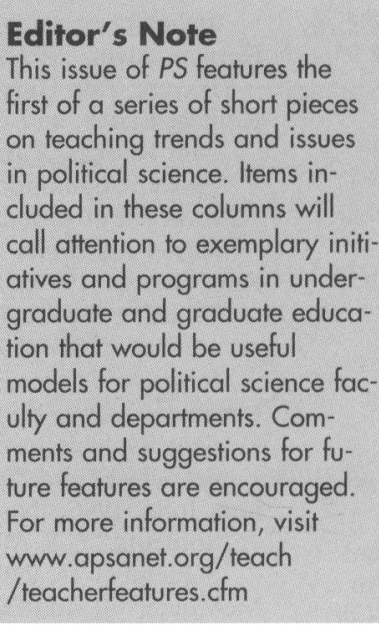

tian students to have a lively and sophisticated discussion on the links between religion and politics. Michael Kenney convinced me that asynchronous bulletin boards made available by WebCT and other software developers can be used to promote more thoughtful discussion, precisely because asynchronous communication gives students time to think before they respond to what the instructor and other students have written. (He also convinced me that it is necessary to grade such participation.)

\section{Creeping Incrementalism}

Assessments of my own teaching, which George Mason's Technology Across the Curriculum project asked me to do, caveats included in the detailed panel presentations, and comments offered by Philip Giddings (who was courses and it can do little to improve learning.

The first is the more embarrassing and I've, thus, in-

asked to join the roundtable because he does have qualms about the use of IT) confirmed two of the worst suspicions about IT: that it can be merely an add-on to tentionally redundantly
labeled it "creeping incrementalism." Since the early 1990s, I have shoehorned more and more technology into my courses, both here and in the UK. However, I have done so without reducing the traditional components, especially the amount of reading I assign. What's more, I have not done much to adapt the written work and other graded projects I assign so I could assess how effectively the IT parts of the course helped students master material.

I certainly did not do this intentionally. However, by adding new components without thinking very clearly about how they fit into my traditional goals as a liberal arts instructor, I have often left my students confused as to what I expected them to focus on.

\section{Another Digital Divide}

There is a lot of talk these days about the digital divide, or the gaps in web access and IT use between rich and poor, black and white, and even men and women. I fear I opened

\footnotetext{
Charles Hauss teaches in the public and international affairs department of George Mason University and is Political Science Guide for About-The Human Internet. He can be reached at polisci.guide@about.com or http://polisci.about.com.
} 
another gap, one between my stronger and weaker students.

Because most of the students I teach work upwards of 30 hours a week while taking four or five courses, I always have a substantial number of students who fail simply be- cause they are unable to keep up with the workload. That proportion has grown in the last two years.

On the other hand, my top students are doing better work than ever. In particular, they use more sophisticated and detailed evidence and make more powerful arguments in large part because my IT use gives them more freedom to pursue their own interests than they would have had had they taken my course before the technology revolution and before I began following more flexible course outlines.

I do not want to overstate the problems. They are serious. Still, the gains far outweigh the costs of using IT in the classroom.

And, both teaching and learning seem to be more fun. 